\title{
Raiva Humana: Optimização da Prevenção e Caminhos \\ Para a Cura
}

\section{Human Rabies: Optimization of Prevention and Paths Towards the Cure}

\author{
Paulo CONCEIÇÃO $\rrbracket^{1}$, Cândida ABREU $2,3,4$ \\ Acta Med Port 2021 Nov;34(11):767-773 - https://doi.org/10.20344/amp.10657
}

\begin{abstract}
RESUMO
Introdução: A raiva é uma das doenças infecciosas mais antigas e fatais conhecidas pelo ser humano e é maioritariamente transmitida por mordeduras de animais. O cão é o principal vector. A raiva não possui uma terapia curativa aprovada e a sua prevenção ainda que possua altas taxas de eficácia, é complexa, dispendiosa e nem sempre conseguida, muito devido às dificuldades de acesso da imunoglobulina. Esta revisão pretende analisar uma abordagem prática de uma prevenção custo-efectiva e as perspectivas futuras em desenvolvimento de uma cura eficaz e segura.
\end{abstract}

Material e Métodos: Foi utilizada a base de dados da PubMed para pesquisa bibliográfica. Usaram-se os termos MeSH: 'rabies', 'preexposure prophylaxis', 'postexposure prophylaxis', 'rabies immune globulin', 'treatment' e 'Milwaukee Protocol'.

Resultados: Relativamente à raiva, é importante executar os protocolos de prevenção atempadamente, devido à imprevisível janela de tempo entre a infecção e a sintomatologia. A literatura mostra que é possível reduzir a dose de vacina mantendo uma eficiente imunização, e que doses de reforço só são necessárias em grupos/populações de risco.

Discussão: A actual filosofia de uma prevenção custo-efectiva, que assenta na vacinação canina, restrição de sobredose das vacinas usadas em seres humanos e o uso inteligente da imunoglobulina rábica - irá permitir maior acessibilidade da prevenção da doença aos países que mais carecem dela. Encontram-se em progresso terapias promissoras, ainda em estadios precoces de estudo.

Conclusão: $O$ desenvolvimento de novas abordagens terapêuticas e profilácticas mais eficazes é um objectivo ainda não alcançado e depende de uma melhor compreensão da patogénese subjacente à doença.

Palavras-chave: Imunoglobulina; Raiva/imunologia; Raiva/prevenção e controlo; Raiva/tratamento; Vacinas Antirrábicas

\section{ABSTRACT}

Introduction: Rabies is one of the oldest and deadliest infectious diseases known by human beings and is commonly transmitted by animal bites. Dogs have a major role in the transmission of the virus. Rabies has no approved curative therapy, and its prevention, even though it is highly effective, it is complex, expensive and challenging in terms of accessibility, particularly regarding immunoglobulin. This review aims to provide a practical approach to cost-effective prevention as well as the future perspectives regarding the development of an effective and secure cure.

Material and Methods: This review article was based on a search in PubMed using the following MeSH terms: rabies, preexposure and postexposure prophylaxis, rabies immune globulin, treatment, Milwaukee Protocol.

Results: Concerning rabies infection, it's important to apply the prevention protocols effectively as early as possible due the unpredictable time window between infection and the appearance of symptoms. The literature shows that is possible to reduce the vaccination dosage and maintain the efficiency of the immunization, and booster vaccination is only required in specific risk groups/populations.

Discussion: The current philosophy of cost-effective prevention which consists of canine vaccination, restriction of vaccine overdosage used in humans and the appropriate use of rabies immunoglobulin - could make the prevention of the disease accessible for those countries that need it the most. There are several therapies in development but they're all in early stages of development.

Conclusion: The development of new and more effective therapeutic and prophylactic approaches is a goal not yet achieved and relies on a better understanding of the disease pathophysiology.

Keywords: Immunoglobulins; Rabies/immunology; Rabies/prevention \& control; Rabies/therapy; Rabies Vaccines

\section{INTRODUÇÃO}

A raiva é uma zoonose milenar ${ }^{1}$ que é transmitida ao ser humano pela mordedura de um animal infectado. Sendo fatal em quase $100 \%$ dos casos após surgimento dos sintomas da doença, resta-nos a profilaxia que pode ser efectuada antes do contacto com o animal rábico (profilaxia pré-exposição) ou após esse contacto (profilaxia pós-exposição). Apesar do actual vasto conhecimento relativo às formas de transmissão e à existência de profilaxia pré e pós-exposição eficazes, estima-se que a raiva continue a ser responsável anualmente pela morte de cerca de 60000 pessoas $^{2}$ e $40 \%$ dessas mortes ocorrem em crianças com menos de 15 anos. ${ }^{3}$ A razão da ocorrência de raiva em seres humanos é essencialmente explicada pela falta de acesso à profilaxia e, principalmente, a um atraso na sua aplicação. A maioria das mortes é observada na Ásia e em África ${ }^{1}$ e $99 \%$ dos casos de raiva humana estão associados à raiva endémica canina ${ }^{3}$; no entanto na América do norte os morcegos são responsáveis por focos de raiva

1. Faculdade de Medicina do Porto. Porto. Portugal.

2. Serviço de Doenças Infeciosas. Centro Hospitalar Universitário São João. Porto. Portugal.

3. Departamento de Medicina. Faculdade de Medicina. Universidade do Porto. Porto. Portugal.

4. Instituto de Inovação e Investigação em Saúde [I3S]. Instituto Nacional de Engenharia Biomédica. Porto. Portugal.

$\triangle$ Autor correspondente: Paulo Conceição. paulo mconceicao@hotmail.com

Recebido: 12 de abril de 2018 - Aceite: 09 de outubro de 2019 - First published: 27 de fevereiro de 2020 - Online issue published: 02 de novembro de 2021 Copyright $\odot$ Ordem dos Médicos 2021 
endémica. ${ }^{4}$

A doença está erradicada em muitos países desenvolvidos, mas o mundo globalizado em que vivemos coloca-nos em risco pela possibilidade de importação da doença de locais onde esta é endémica.

Mas o que está a ser feito para estabelecer uma estratégia de tratamento eficaz da doença rábica humana?

O ano de 2004 marcou o que pode ser considerado uma nova forma de abordagem terapêutica. Nesse ano, surgiu o primeiro caso documentado de cura após início da sintomatologia, ${ }^{5}$ baseado na utilização de uma nova estratégia terapêutica que incluiu a indução de coma terapêutico e ficou conhecida como Protocolo de Milwaukee.

É sobre a evolução e alternativas terapêuticas e preventivas na raiva a que se dedica este manuscrito, pretendendo fazer uma actualização do tema, que seja útil como instrumento prático de orientação clínica na prevenção da doença e que actualize as linhas de tratamento em investigação.

\section{MATERIAL E MÉTODOS}

Procedeu-se à pesquisa bibliográfica utilizando a base de dados da PubMed. A pesquisa foi feita com o uso de MeSH terms usando as seguintes combinações: 'rabies', 'preexposure prophylaxis', 'postexposure prophylaxis', 'vaccine', 'rabies immune globulin', 'treatment' e 'Milwaukee Protocol'.

Após leitura dos abstracts dos 54 artigos encontrados foram seleccionados para leitura integral 47 que se enquadravam nos objetivos deste artigo.

\section{A geografia da doença}

A raiva é um problema de saúde pública em mais de 150 países em desenvolvimento no mundo ${ }^{3}$ e uma causa frequente de morte, sobretudo em países africanos e asiáticos. É na Ásia que ocorre maior número de mortes por ano, estimando-se que em 2003 esse número tenha ultrapassado as 30000 mortes. $^{1}$

Apesar de erradicada em Portugal desde 1960, o mundo globalizado em que vivemos coloca-nos em risco da doença. O último caso de raiva humana no país ocorreu em 2011, numa mulher residente na Amadora, tendo sido um caso de importação da Guiné-Bissau. Foi utilizado o Protocolo de Milwaukee, contudo este demonstrou-se ineficaz e a mulher acabou por falecer duas semanas após o diagnóstico da doença. Esse foi o único caso de raiva da Europa registado em 2011. ${ }^{6}$ Entre 1990 e 2010 foram contabilizadas um total de 42 mortes pelo vírus da raiva na Europa, EUA e Japão, tendo todos sido assumidos como doença importada, ${ }^{7}$ o que nos leva a uma média de duas mortes por ano.

\section{Do vírus às manifestações clínicas e ao diagnóstico}

O agente etiológico é um vírus de RNA pertencente ao género Lyssavirus e à família Rhabdoviridae ${ }^{8}$ e tem sete genótipos identificados. ${ }^{9}$ Os genótipos 1 e entre o 3 e 07 são responsáveis pela raiva em humanos. O genótipo 3 é o mais raro, tendo sido identificado apenas em duas ocasiões. ${ }^{10}$

O vírus é introduzido no hospedeiro humano pela mordedura ou pelo contacto directo com a mucosa, contudo o vírus não é capaz de atravessar a pele intacta. No músculo, o vírus replica-se e utiliza as placas motoras e os neurónios motores como ponte para acesso ao sistema nervoso central. ${ }^{11,12}$

O período de incubação é extremamente variável, desde poucos dias até vários anos após contracção do vírus. Porém, o tempo de janela mais comum é entre um e dois meses após infeção. ${ }^{9,13}$ Existe uma correlação entre o local de mordedura e o tempo de incubação que tem que ver com a inervação do local da mordedura e a sua distância ao sistema nervoso central, de tal maneira que, mordeduras na cabeça, pescoço, mãos e genitais estão associados a períodos de incubação mais curtos. ${ }^{14}$

A fase prodrómica segue-se ao período de incubação: tem uma duração média de 10 dias e manifesta-se com sintomas inespecíficos, tais como perda de apetite, astenia, cefaleias, ansiedade, insónia e febre.

A fase neurológica pode manifestar-se de duas formas: (a) raiva encefalítica (cerca de $80 \%$ dos casos), caracterizada por períodos de hiperexcitabilidade separados por momentos de lucidez, ${ }^{15}$ hipersalivação, suores, transpiração, ereção pilosa e hidrofobia em $50 \%$ - $80 \%$ deste grupo ${ }^{15,16}$ : e (b) raiva paralítica (em cerca de $20 \%$ dos casos), caracterizada por fraqueza inicial do membro mordido que evolui para quadriparésia com envolvimento esfincteriano e tem tempo de sobrevida maior do que a raiva encefalítica. ${ }^{17}$ A esta fase segue-se o coma e a morte.

As manifestações clínicas num doente levam-nos a suspeitar do diagnóstico de raiva (caso 'possível'), e a clínica mais a certeza de contacto com um animal infectado com raiva configuram o caso 'provável'. Contudo, só os testes laboratoriais positivos na presença de clínica e epidemiologia asseguram o caso 'confirmado'.

Os critérios laboratoriais para confirmação da raiva estão assentes em pelo menos um dos seguintes: a presença de antigénios virais nos tecidos (tipicamente por biópsia da pele da nuca), a presença de anticorpos específicos no sangue e fluido cefalorraquidiano e a detecção de antigénios virais em biopsia, saliva ou urina e o isolamento de vírus em cultura. ${ }^{18}$

\section{Uma tentativa terapêutica: o Protocolo de Milwaukee}

À estratégia terapêutica utilizada em 2004, que levou à cura de uma adolescente norte americana infectada, que não tinha feito profilaxia da doença, chamou-se Protocolo de Milwaukee. ${ }^{5}$

O Protocolo de Milwaukee fundamentou-se em três passos: indução de coma terapêutico, infusão de quetamina e utilização do antivírico amantadina com rastreio, vigilância e terapêutica do vasospasmo cerebral. Porém, depois do resultado registado com o Protocolo de Milwaukee, foram feitas várias tentativas e alterações à metodologia de modo a reproduzir o feito, mas com muito pouco sucesso e com 
uma base científica de metodologia muito frágil, ${ }^{19,20}$ que levou a que este protocolo fosse abandonado.

\section{Prevenção: a pedra basilar}

Sem terapêutica eficaz, o controlo da raiva fundamenta-se na prevenção que se baseia em duas estratégias principais: (a) vacinação de cães, de modo a prevenir a principal fonte de transmissão aos seres humanos, estando demonstrado que a vacinação canina é o modelo mais custo-efectivo de prevenção da raiva humana ${ }^{21}$ e (b) vacinação humana, dividida na profilaxia pré-exposição (PPrE) e na profilaxia pós-exposição (PPE) (Fig. 1).

\section{a) Imunização: a vacina}

A vacina da raiva é uma vacina inactivada preparada em cultura de células embrionárias purificadas de pinto (VCCEPP). Há várias VCCEPP que são eficazes e seguras na prevenção da raiva. Estas vacinas são administradas tanto na PPrE, como na PPE. Das muitas vacinas existentes, apenas três fazem parte da pré-qualificação da Organização Mundial de Saúde (OMS): Rabavert ${ }^{\circledR}$ e Rabipur ${ }^{\circledR}$ (vacinas baseadas em ovos embrionados) e Verorab $^{\circledR}$ (vacina purificada em cultura de células).$^{22}$

Estas vacinas são extremamente bem toleradas e não têm contra-indicações, incluindo administração em crianças, grávidas e imunodeprimidos.

A eficácia dos regimes de vacinação, quando administrados adequadamente, aproxima-se de $100 \% .{ }^{23}$ Presume- -se que as VCCEPP estabelecem imunidade de memória que persiste a vida inteira, mesmo com declínio dos anticorpos mensuráveis, e não está provado que exista uma relação entre o tempo decorrido desde a imunização e a quantificação de anticorpos. ${ }^{24,25}$ Por rotina, doses de reforço não são preconizadas, excepto nos indivíduos que têm exposição continuada e que por isso têm indicação para fazer PPrE (Tabela 1). ${ }^{26}$

b) Vacina na pré-exposição - PPrE: quando e como? Indivíduos que se encontrem em constante risco de infecção pelo vírus, tais como habitantes em áreas endémicas, indivíduos com risco ocupacional e viajantes com exposição significativa em zonas com raiva endémica (Tabela 1) têm indicação para fazer PPrE.

A PPrE não é custo-efetiva a nível populacional e só deveria ser considerada em casos seleccionados, como locais onde a exposição à raiva é excepcionalmente alta (> $6 \%$ ), e a Imunoglobulina rábica (IGR) é escassa. ${ }^{22}$

A PPrE consiste numa série de vacinas contra a raiva que prepara o sistema imune para uma resposta mais rápida, caso haja exposição ao vírus. A PPrE torna a administração de imunoglobulinas desnecessária após mordedura, excepto nos indivíduos com compromisso imunitário. Um indivíduo é considerado imunodeprimido quando: está medicado com glicocorticóides há mais de três semanas (em doses superiores a $20 \mathrm{mg} / \mathrm{dia}$ de prednisolona ou equivalente), inibidores da calcineurina (ciclosporina, tacrolimus),

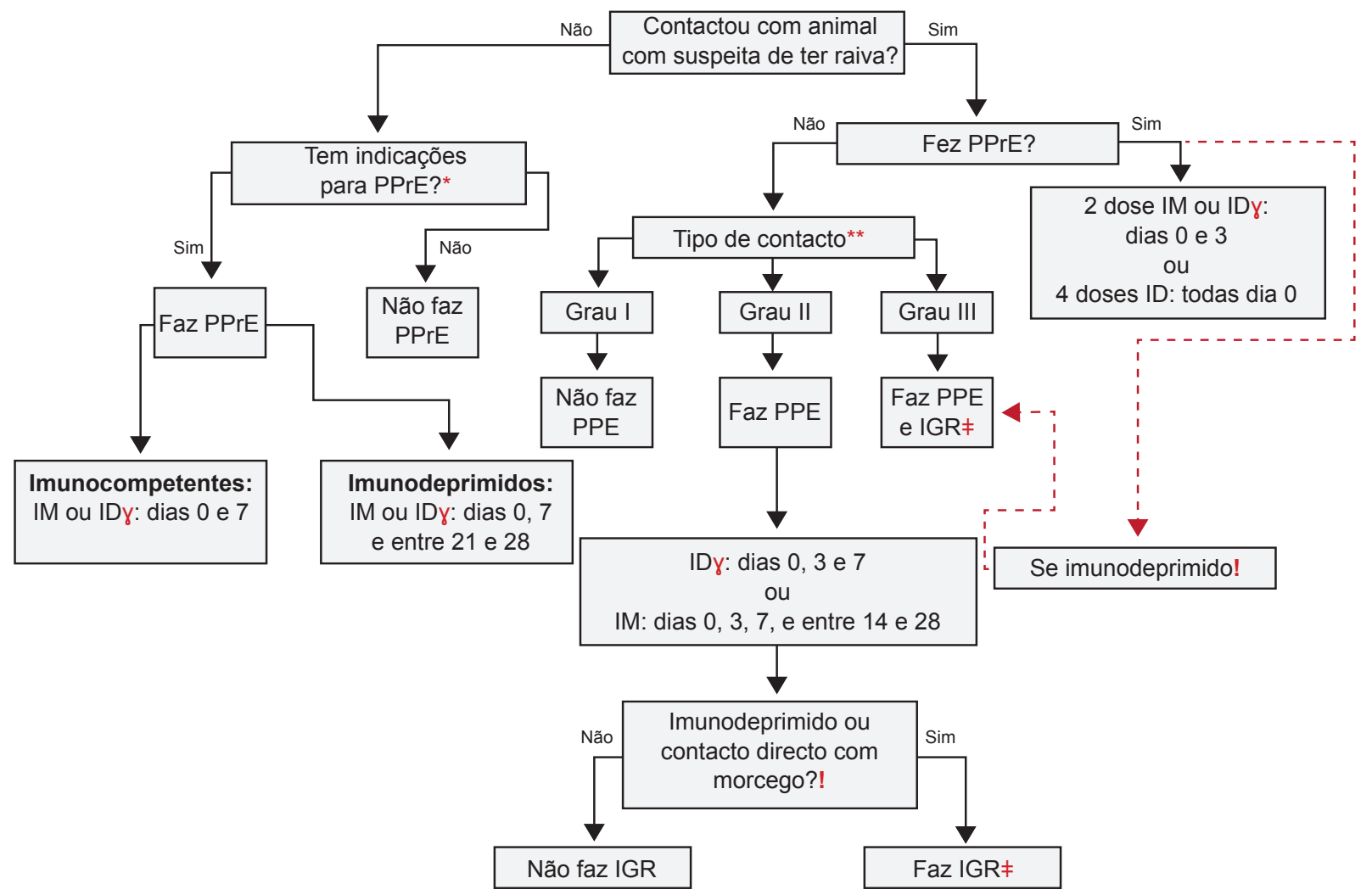

Figura 1 - Diagrama de acção: como agir na suspeita de um caso de raiva

*: ver Tabela 1; **: ver Tabela 2; y: administração dividida em dois locais; ¥: IGR deve ser feita nos primeiros sete dias aquando da primeira administração de vacina; ID: Intradérmico; IM: Intramuscular; IGR: Imunoglobina rábica; PPrE: Profilaxia pré-exposição; PPE: Profilaxia pós-exposição; !: No contacto directo com morcegos e em indíviduos imunodeprimidos está indicado o regimen clássico de PPE. 
Tabela 1 - Indicações para profilaxia pré-exposição da raiva e doses de reforço

Indivíduos envolvidos no estudo da raiva e com acesso a produtos biológicos.

Trabalhadores em: laboratórios de diagnóstico de raiva, hospitais com casos de raiva, canis, zonas selvagens, empresas de exterminação de morcegos; veterinários

Residentes ou trabalhadores em zonas remotas e por longos períodos.

Viajantes para zonas endémicas e com risco elevado de infecção."

"Doses de reforço não são aconselhadas em viajantes. ${ }^{30}$

tiopurinas, ciclofosfamida, metotrexato, clorambucil, micofenolato de mofetil e anti TNF-alfa e outros fármacos biológicos assim como os novos imunomoduladores, ${ }^{27}$ quando sofre de uma imunodeficiência primária ou no caso da infeção pelo vírus da imunodeficiência humana com défice imunitário (sem tratamento e sem reconstituição imunitária).

Os seguintes regimes acelerados de PPrE (Fig.1) provaram-se tão eficazes como os regimes clássicos de três doses: duas administrações de duas doses intradérmicas (ID) nos dias 0 e 7 ou duas administrações de uma dose intramuscular (IM) nos dias 0 e $7 .{ }^{22}$ Estes regimes acelerados são aprovados pela OMS mas ainda não se encontram aprovados pelo $\mathrm{CDC}^{28}$ que preconiza o regime clássico de três administrações: uma dose IM ou duas doses ID nos dias 0,7 e 21 a $28 .{ }^{28}$ Aguarda-se que em 2019 sejam aprovados pelo CDC os regimes acelerados de PPrE.

Contudo, nos indivíduos imunocomprometidos que possuem uma resposta imune mais débil, está preconizado manter um regime clássico de três administrações: uma dose IM nos dias 0, 7 e 21 a 28; ou duas doses ID nos dias 0,7 e 21 a 28.22

\section{c) Imunoglobulina rábica (IGR) na PPE: quando e como?}

A IGR é um método de imunização passiva e é utilizada como componente da PPE. A IGR vai neutralizar o vírus in situ, antes que o sistema imune do indivíduo consiga responder à vacinação, produzindo anticorpos que neutralizarão o vírus.$^{29}$ Esta imunização passiva impede que o vírus penetre no sistema nervoso. Contudo, a IGR perde o seu efeito caso o vírus ultrapasse esta barreira antes de ser administrada.

Existem dois tipos de IGR: a IGR humana (IGRh) e a equina (IGRe) que são consideradas clinicamente equivalentes. Apesar de serem necessárias maiores doses de IGRe, devido à sua menor biodisponibilidade, esta é tida como uma alternativa menos dispendiosa. ${ }^{18}$ Mantém-se a recomendação de que o cálculo para dosagem máxima de IGR seja baseada no peso, ${ }^{30,31}$ sendo a dose a administrar de $20 \mathrm{UI} / \mathrm{kg}$ para a IGRh e $40 \mathrm{UI} / \mathrm{kg}$ para a IGRe. Como parte da PEP, a IGR deve ser administrada aquando da primeira toma da vacina. Não é aconselhado fazer IGR após o sétimo dia depois da primeira toma da vacina, pois nesta altura já existe uma resposta imunológica da VCCEPP, podendo ocorrer interferência e portanto diminuição da resposta protectora entre a imunização activa e passiva. ${ }^{22}$

Recomenda-se que o local de administração de IGR seja na ferida rábica e ao seu redor.

Os efeitos laterais da IGR são muito variados: exantema, pele ruborizada no local de aplicação, mialgias e até hipotensão e dispneia que pode culminar em choque. Porém, os efeitos adversos mais graves ocorrem muito raramente, sendo a IGR considerada bastante segura.

Sendo a IGR dispendiosa e por vezes difícil de obter, há estudos que mostram que, na ausência de IGR, com uma lavagem rigorosa da ferida juntamente com a administração de vacinas no mesmo dia da mordedura e cumprimento de regime PPE posterior se produz uma protecção eficaz contra a raiva em $95 \%$ dos casos. $^{32,33}$

\section{d) Vacinas versus vacinas e IGR na PPE (Fig. 1)}

A indicação para fazer PPE vai depender do tipo de contacto que o indivíduo tem com o animal infectado (Tabela 2). A PPE está indicada nos indivíduos com exposição à saliva de animal rábico de tipos II e III e deve ser iniciada o mais atempadamente possível. Inclui limpeza apropriada da ferida seguida de uma série de injecções de vacina

Tabela 2 - Tipo de contacto com animal rábico ${ }^{19}$

\begin{tabular}{lll}
\hline Tipo de exposição & Detalhe da exposição & Medidas a instituir \\
\hline Tipo I & $\begin{array}{l}\text { Tocar ou alimentar animais. Contacto com } \\
\text { saliva ou outras secreções de animal/ } \\
\text { humano infectado em pele intacta. }\end{array}$ & $\begin{array}{l}\text { Estas não são consideradas exposições ao vírus, logo não } \\
\text { necessitam de PEP. }\end{array}$ \\
Tipo II & $\begin{array}{l}\text { Leves mordeduras e arranhadelas sem } \\
\text { sangramento. }\end{array}$ & $\begin{array}{l}\text { Vacina deve ser administrada o mais rapidamente possível. } \\
\text { A imunoglobulina deve ser administrada se o indivíduo for } \\
\text { imunodeprimido ou ocorrer exposição directa com morcegos. }\end{array}$ \\
& $\begin{array}{l}\text { Mordeduras penetrantes, contacto com } \\
\text { saliva de animal infectado em pele lesada } \\
\text { e exposição a morcegos. }\end{array}$ & $\begin{array}{l}\text { Vacina e imunoglobulina devem ser administradas o mais } \\
\text { rapidamente possível. }\end{array}$ \\
\hline
\end{tabular}


contra a raiva e administração de imunoglobulina, se não tiver sido feita PPrE. ${ }^{29}$

A IGR deve ser administrada em todos os indivíduos na exposição de tipo III, nos indivíduos com exposição de tipo Il que não tenham feito PPrE e nos imunodeprimidos.

Todas as feridas, inclusive as mais pequenas, devem receber uma infiltração com IGR.

O regime de PPE ID acelerado de três administrações de duas doses ID nos dias 0, 3 e 7 (regime usado no Pasteur Institute of Cambodia) mostrou-se tão eficaz como os regimes actuais de PPE utilizados de quatro administrações de duas doses ID nos dias 0, 3, 7 e entre o dia 14 e $28 .{ }^{34}$ Até à data, não existem dados que apoiem a redução dos regimes IM de quatro administrações de uma dose IM nos dias $0,3,7$ e entre os dias 14 e $28 .^{22}$

Se ocorrer contacto, mas tiver sido feita PPrE previamente, faz-se PPE com as seguintes opções: duas doses ID ou IM de PPE nos dias 0 e 3; ou uma administração de quatro doses ID de PPE no dia 0.

Alterar a via de administração, de ID para IM ou vice-versa, durante a PPE é uma medida aceitável, em caso de circunstâncias inevitáveis. Nestes casos, não é necessário reiniciar a PPE, mas apenas se continua o regime com a nova via de administração. ${ }^{35,36}$

A PPE é eficaz e, acima de tudo, segura mesmo em grávidas e imunodeprimidos.

\section{e) Via intradérmica versus via intramuscular}

A via IM da vacina tem sido opção a mais utilizada nos protocolos de profilaxia da raiva, figurando apenas esta via de administração no protocolo de actuação em Portugal na suspeita de indivíduo infectado com raiva. Contudo, os custos inerentes a este tipo de vacina limitam a sua distribuição a várias áreas endémicas da doença. As vacinas ID surgem como uma alternativa mais económica às IM, sem que haja comprometimento de eficácia imunogénica. Dado o menor volume utilizado na vacina ID, há uma redução do custo de $60 \%$ - 80\% em comparação com a clássica injecção IM. ${ }^{18}$ Desta forma, a via ID permite resposta imunogénica equivalente com o uso de doses menores de vacina, sendo que uma dose ID de $0,1 \mathrm{ml}$ da vacina representa entre um quinto a um décimo de uma dose IM.

Apesar das várias vantagens disponíveis com o uso da via ID, o seu uso não está recomendado em indivíduos com défice imunitário, dado o possível compromisso da apresentação de antigénios vacinais e da resposta específica aos antigénios apresentados nestas situações. ${ }^{37}$

\section{$\cos$ \\ f) Prevenção da raiva em portugal: aspectos práti-}

A vacina inactivada utilizada em Portugal é a Rabipur ${ }^{\circledR}$ e é de administração IM. É uma vacina não comparticipada e que exige receita médica no caso da PPrE.

Havendo a necessidade de fazer PPE, é importante estar informado acerca dos protocolos de actuação em Portugal no que concerne à profilaxia pós-exposição. Os critérios de inclusão utilizados na administração da IGR na
PPE dependem do tipo de contacto com o animal infectado e são os mesmos utilizados pela OMS (Tabela 2). Um médico que identifique uma pessoa com exposição provável a animal rábico, deve contactar o Centro Anti-Rábico Nacional, Serviço de Doenças Infecciosas do Centro Hospitalar de Lisboa Norte (telemóvel 962588 876), para que o pedido da IGR seja validado. Após validação, o serviço requisitante envia por email/fax o formulário de prescrição preenchido para o Centro Anti-Rábico Nacional que, após recepção do formulário, cede a IGR, ficando o transporte do medicamento ao encargo do serviço requisitante. ${ }^{38}$ Nestas situações de PPE, a vacina é administrada gratuitamente, fornecida pelo Centro Anti-Rábico Nacional, e administrada de acordo com o regime protocolado - administração intramuscular da vacina nos dias $0,3,7$ e entre 14 e 28 .

\section{Perspectivas futuras}

\section{a) Prevenção}

Está em estudo a concepção de vacinas atenuadas, que teriam benefícios superiores às vacinas inactivadas actualmente em uso. Entre esses benefícios, realça-se o facto de, para além de induzir uma resposta humoral do tipo das vacinas inactivadas (por activação das células T CD4+), estas também seriam capazes de induzir uma resposta imune inata (por activação de células T CD8+), desempenhando um papel fundamental na resposta imune celular contra a infecção viral. ${ }^{39}$ Esta também seria uma opção economicamente vantajosa, pois permitiria uma imunidade a longo prazo com apenas uma única dose. ${ }^{40}$

Tendo em conta os custos de produção e da dificuldade de acesso à IGR, muitos estudos vêem os anticorpos monoclonais como alternativa mais sustentável. O produto em estado de desenvolvimento mais avançado denomina-se Rabishield ${ }^{\mathrm{TM}}$ e é um anticorpo monoclonal do tipo lgG1 humano. Este tem a capacidade de se ligar a um epítopo da glicoproteína rábica. ${ }^{41}$ Este estudo demonstrou que uma dose de $10 \mathrm{UI} / \mathrm{kg}$ de Rabishield ${ }^{\mathrm{TM}}$ produz imunidade equiparável a $20 \mathrm{UI} / \mathrm{kg}$ de IGR. ${ }^{42}$ Sendo este o único anticorpo monoclonal licenciado e dadas as limitações de acesso à IGR, o seu uso está autorizado em zonas geográficas seleccionadas. ${ }^{22}$

\section{b) Tratamento}

Um dos problemas no tratamento da doença prende-se com o facto de não haver tratamento assim que o vírus atinge o sistema nervoso central, pois tanto as actuais vacinas como a IGR não conseguem penetrar a barreira hematoencefálica (BHE). Uma das investigações em curso, em ratinhos, consiste em aumentar a permeabilidade da BHE de modo a ultrapassar esta dificuldade..$^{43,44}$ Contudo, apesar de ter ocorrido um aumento da sobrevida dos ratinhos, os estudos levantaram algumas preocupações a nível de segurança, nomeadamente, o comprometimento da integridade do sistema nervoso central. ${ }^{40}$

Os anticorpos bi-específicos (AcBe) também são uma opção promissora no tratamento da raiva. Estes anticorpos são dos últimos avanços da imunoterapia do cancro. ${ }^{45}$ 
Cada anticorpo é composto por duas regiões de ligação para dois antigénios diferentes, ou para dois epítopos de um único antigénio. Teoricamente, os AcBe seriam capazes de atravessar a BHE e de neutralizar o vírus no SNC.

\section{DISCUSSÃO}

A raiva humana é uma doença fatal e que afeta sobretudo países de baixos recursos; numa revisão deste tipo as limitações são evidentes pela dificuldade em englobar todos os estudos e resultados que podem vir a ter mais potencial, da prevenção à terapêutica. Apesar da vacinação dos cães constituir um pilar da estratégia da OMS para extinguir as mortes humanas causadas por raiva de transmissão canina até $2030,{ }^{46}$ a imunização humana continua a ser essencial para salvar vidas. Na ausência de PPE, estima-se que cerca de três milhões de pessoas morreriam por ano, vítimas de raiva ${ }^{47}$ As recomendações para PPrE e PPE da OMS têm-se provado difíceis de implementar, de tal modo que menos de $1 \%$ dos doentes na exposição de tipo III recebem a IGR nos países onde a doença é endémica. ${ }^{48}$ Os principais obstáculos na implementação da PPE incluem regimes de vacina prolongados e complicados, para além dos elevados custos económicos, da baixa demanda, disponibilidade, variabilidade na qualidade dos stocks e o curto tempo de validade da IGR. Dados publicados recentemente apoiam o uso de um algoritmo de casos prioritários, de forma a usar a IGR de forma mais prudente e equitativa. Acredita-se que este método iria facilitar tanto em termos logísticos como éticos. Optando por uma vacina ID e acoplá-la a um regime acelerado de profilaxia permitiria, não só focar os recursos nos casos mais urgentes, como também aumentar os recursos disponíveis. Desta forma, seria possível imunizar mais pessoas do que as que são vacinadas actualmente, principalmente onde a doença é endémica.

Apesar do Protocolo de Milwaukee ter sido uma tentativa infrutífera de cura da doença, esta levou a considerações e a conclusões que são importantes considerar ${ }^{12}$ : (a) a raiva não é invariavelmente fatal em animais, mas apenas um pequeno número de humanos recuperou da doença; (b) actualmente não é possível prever quais os doentes que irão recuperar; (c) todos os sobreviventes, com ou sem tratamento, tiveram uma resposta imunológica precoce e robusta; (d) são encorajados novos estudos para criar novos protocolos e novas terapêuticas farmacológicas; (e) os tratamentos humanos devem ser seguros e o mais possível isentos de riscos.

\section{CONCLUSÃO}

Apesar de negligenciada, a raiva continua a ser uma doença de impacto, maioritariamente em países de baixos recursos devido sobretudo à infecção endémica canina. Para a OMS, a vacinação canina é atualmente um factor-chave de erradicação da doença. Na pré-exposição à raiva a indicação da administração de duas e não três doses de vacina, separadas por uma semana vem simplificar a profilaxia e diminuir os custos. Qualquer contacto com a doença deve ser investigado e a profilaxia deve ser impe- rativamente aplicada atempadamente. Uma priorização na administração da PPE e a prática de regimes de profilaxia acelerada com três administrações de vacina ID simplificam o habitual esquema das quatro doses de vacina IM. As vacinas ID nas pessoas sem compromisso de imunidade são mais económicas e permitem uma administração de menor volume de antigénio.

Mais recentemente, começaram-se a utilizar anticorpos monoclonais, como o Rabishield ${ }^{\mathrm{TM}}$, na prevenção da doença rábica. Esta não só se provou como medida preventiva eficaz, como também constitui uma alternativa mais económica comparativamente à IGR. Sendo o Rabishield ${ }^{T M} \mathrm{o}$ único anticorpo monoclonal licenciado de momento, torna-se importante que outros anticorpos em estudo completem todas as fases de ensaios clínicos de modo a aumentar o leque das opções preventivas da doença.

Os objectivos futuros prendem-se, não só com o desenvolvimento de terapêutica curativa para uma doença ainda incurável após início da sintomatologia, mas também com a disponibilização de vacinas que necessitem de menores doses de carga e de um menor número de administrações sem comprometimento da eficácia, tornando-se assim mais económico e, consequentemente, mais acessível àqueles que mais carecem dela. As vacinas atenuadas poderão vir a ser uma melhor opção pela sua maior imunogenicidade. Relativamente ao tratamento da doença, os anticorpos biespecíficos são uma esperança, pela possibilidade de atuarem no vírus depois de ultrapassada a barreira hematoencefálica. Cremos que uma melhor compreensão da patofisiologia da doença será o ponto de partida para novas e melhores vacinas e um tratamento etiotrópico eficaz, que possa fazer da raiva uma doença mais facilmente prevenível e potencialmente curável.

\section{CONTRIBUTO DOS AUTORES}

PC: Seleção e revisão dos manuscritos, redação do artigo.

CA: Contributo significativo na redação do manuscrito e na sua revisão crítica.

\section{PROTECÇÃO DE PESSOAS E ANIMAIS}

Os autores declaram que os procedimentos seguidos estavam de acordo com os regulamentos estabelecidos pelos responsáveis da Comissão de Investigação Clínica e Ética e de acordo com a Declaração de Helsínquia da Associação Médica Mundial.

\section{CONFIDENCIALIDADE DOS DADOS}

Os autores declaram ter seguido os protocolos do seu centro de trabalho acerca da publicação de dados.

\section{CONFLITOS DE INTERESSE}

Os autores declaram não nenhum conflito de interesse.

\section{FONTES DE FINANCIAMENTO}

Os autores declaram não ter tido suporte financeiro. 


\section{REFERÊNCIAS}

1. Knobel DL, Cleaveland S, Coleman PG, Févre EM, Meltzer MI, Miranda $\mathrm{ME}$, et al Re-evaluating the burden of rabies in Africa and Asia. Bull World Health Organ. 2005;83:360-8.

2. Jackson AC. Human rabies: a 2016 update. Curr Infect Dis Rep. 2016;18:38.

3. World Health Organization. Rabies fact sheet updated September 2017. [consultado 2017 jul 11]. Disponível em: https://www.who.int/newsroom/fact-sheets/detail/rabies.

4. Monroe BP, Yager P, Blanton J, Birhane MG, Wadhwa A, Orciari L, et al. Rabies surveillance in the United States during 2014. J Am Vet Med Assoc. 2016;248:777-88.

5. Willoughby RE Jr, Tieves KS, Hoffman GM, Ghanayem NS, AmlieLefond CM, Schwabe MJ, et al. Survival after treatment of rabies with induction of coma. N Engl J Med. 2005;352:2508-14.

6. Santos A, Cale E, Dacheux L, Bourhy H, Gouveia J, Vasconcelos P. Fatal case of imported human rabies in Amadora, Portugal, August 2011. Euro Surveill. 2012;17:pii:20130.

7. Malerczyk C, Detora L, Gniel D. Imported human rabies cases in europe, the United States, and Japan, 1990 to 2010. J Travel Med. 2011;18:4027.

8. Rupprecht CE, Gibbons RV. Clinical practice. Prophylaxis against rabies. N Engl J Med. 2004;351:2626-35.

9. Hemachudha T, Laothamatas J, Rupprecht CE. Human rabies: a disease of complex neuropathogenetic mechanisms and diagnostic challenges. Lancet Neurol. 2002;1:101-9.

10. Amsden Jr WT, Gubbins PO. Zoonoses. In: Schumock GT, Dunsworth TS, Brundage DM, editors. Pharmacotherapy self-assessment program. Am Coll Clin Pharm. 2004:1-42.

11. Ugolini G. Use of rabies virus as a transneuronal tracer of neuronal connections: implications for the understanding of rabies pathogenesis. Dev Biol. 2008;131:493-506.

12. Hemachudha T, Ugolini G, Wacharapluesadee S, Sungkarat W, Shuangshoti S, Laothamatas J. Human rabies: neuropathogenesis, diagnosis, and management. Lancet Neurol. 2013;12:498-513.

13. Leung AK, Davies HD, Hon KL. Rabies: epidemiology, pathogenesis, and prophylaxis. Adv Ther. 2007;24:1340-7.

14. Cleaveland S, Fevre EM, Kaare M, Coleman PG. Estimating human rabies mortality in the United Republic of Tanzania from dog bite injuries. Bull World Health Organ. 2002;80:304-10.

15. Warrell DA. The clinical picture of rabies in man. Trans $R$ Soc Trop Med Hyg. 1976;70:188-95.

16. Warrell DA, Davidson NM, Pope HM, Bailie WE, Lawrie JH, Ormerod LD, et al Pathophysiologic studies in human rabies. Am J Med. 1976;60:18090.

17. Udow SJ, Marrie RA, Jackson AC. Clinical features of dog- and batacquired rabies in humans. Clin Infect Dis. 2013;57:689-96.

18. World Health Organization. Expert consultation on rabies: second report. 2013. [consultado 2018 jan 10]. Disponível em: https://apps.who. int/iris/handle/10665/85346.

19. Aramburo A, Willoughby RE, Bollen AW, Glaser CA, Hsieh CJ, Davis SL, et al. Failure of the Milwaukee protocol in a child with rabies. Clin Infect Dis. 2011;53:572-4.

20. Zeiler FA, Jackson AC. Critical appraisal of the Milwaukee protocol for rabies: this failed approach should be abandoned. Can J Neurol Sci. 2016;43:44-51.

21. Davlin SL, Vonville HM. Canine rabies vaccination and domestic dog population characteristics in the developing world: a systematic review. Vaccine. 2012;30:3492-502.

22. SAGE Working Group on Rabies WHOW. Background paper: proposed revision of the policy on rabies vaccines and rabies immunoglobulins. [consultado 2017 jul 11]. Disponível em: https://www.who.int/ immunization/sage/meetings/2017/october/1_Background_paper_WG_ RABIES final.pdf?ua=1.

23. Warrell $\bar{M} J$, Nicholson KG, Warrell DA, Suntharasamai $P$, Chanthavanich $\mathrm{P}$, Viravan $\mathrm{C}$, et al Economical multiple-site intradermal immunisation with human diploid-cell-strain vaccine is effective for post-exposure rabies prophylaxis. Lancet. 1985;1:1059-62.

24. Brown D, Featherstone JJ, Fooks AR, Gettner S, Lloyd E, Schweiger M Intradermal pre-exposure rabies vaccine elicits long lasting immunity. Vaccine. 2008;26:3909-12

25. Naraporn N, Khawplod P, Limsuwan K, Thipkong P, Herzog C, Glueck $\mathrm{R}$, et al Immune response to rabies booster vaccination in subjects who had postexposure treatment more than 5 years previously. J Travel Med. 1999;6:134-6.

26. Strady A, Lang J, Lienard M, Blondeau C, Jaussaud R, Plotkin SA.
Antibody persistence following preexposure regimens of cell-culture rabies vaccines: 10-year follow-up and proposal for a new booster policy. J Infect Dis. 1998;177:1290-5.

27. Rahier JF, Moutschen M, Van Gompel A, Van Ranst M, Louis E, Segaert $S$, et al Vaccinations in patients with immune-mediated inflammatory diseases. Rheumatology. 2010;49:1815-27.

28. Centers for Disease Control and Prevention. Rabies vaccine what you need to know. In: CDC, ed, 2009. [consultado 2017 nov 23]. Disponível em: https://www.cdc.gov/vaccines/hcp/vis/vis-statements/rabies.html.

29. Nigg AJ, Walker PL. Overview, prevention, and treatment of rabies. Pharmacotherapy. 2009;29:1182-95.

30. Bharti OK, Madhusudana SN, Gaunta PL, Belludi AY. Local infiltration of rabies immunoglobulins without systemic intramuscular administration: an alternative cost effective approach for passive immunization against rabies. Hum Vaccin Immunother. 2016;12:837-42.

31. Madhusudana SN, Ashwin BY, Sudarshan S. Feasibility of reducing rabies immunoglobulin dosage for passive immunization against rabies: results of In vitro and In vivo studies. Hum Vaccin Immunother. 2013;9:1914-7.

32. Shantavasinkul P, Wilde H. Postexposure prophylaxis for rabies in resource-limited/poor countries. Adv Virus Res. 2011;79:291-307.

33. Wilde H, Khawplod P, Hemachudha T, Sitprija V. Postexposure treatment of rabies infection: can it be done without immunoglobulin? Clin Infect Dis. 2002;34:477-80.

34. Tarantola A, Ly S, Chan M, In S, Peng Y, Hing C, et al. Intradermal rabies post-exposure prophylaxis can be abridged with no measurable impact on clinical outcome in Cambodia, 2003-2014. Vaccine. 2019;37:A11827.

35. Ravish HS, Sudarshan MK, Madhusudana SN, Annadani RR, Narayana $\mathrm{DH}$, Belludi AY, et al. Assessing safety and immunogenicity of postexposure prophylaxis following interchangeability of rabies vaccines in humans. Hum Vaccin Immunother. 2014;10:1354-8.

36. Sudarshan MK. Introducing intradermal rabies vaccination in India: paradigm shift for the better. Indian J Public Health. 2006;50:209-12.

37. Tantawichien T, Jaijaroensup W, Khawplod P, Sitprija V. Failure of multiple-site intradermal postexposure rabies vaccination in patients with human immunodeficiency virus with low CD4+ T lymphocyte counts. Clin Infect Dis. 2001;33:E122-4.

38. Direcção Geral de Saúde. Procedimento para disponibilização da reserva estratégica nacional de imunoglobulina contra a raiva (REN IgR). 2017. [consultado 2017 dez 19]. Disponível em: https://www.dgs. $\mathrm{pt} /$ ?ci=1010\&ur=1\&newsletter=391.

39. Griffin DE, Metcalf T. Clearance of virus infection from the CNS. Curr Opin Virol. 2011;1:216-21.

40. Zhu S, Guo C. Rabies control and treatment: from prophylaxis to strategies with curative potential. Viruses. 2016;8:pii: E279.

41. Gogtay NJ, Munshi R, Ashwath Narayana DH, Mahendra BJ, Kshirsagar V, Gunale B, et al. Comparison of a novel human rabies monoclonal antibody to human rabies immunoglobulin for postexposure prophylaxis: a phase $2 / 3$, randomized, single-blind, noninferiority, controlled study. Clin Infect Dis. 2018;66:387-95.

42. Gogtay N, Thatte U, Kshirsagar N, Leav B, Molrine D, Cheslock P, et al. Safety and pharmacokinetics of a human monoclonal antibody to rabies virus: a randomized, dose-escalation phase 1 study in adults. Vaccine. 2012;30:7315-20.

43. Huang CT, Li Z, Huang Y, Zhang G, Zhou M, Chai Q, et al. Enhancement of blood-brain barrier permeability is required for intravenously administered virus neutralizing antibodies to clear an established rabies virus infection from the brain and prevent the development of rabies in mice. Antiviral Res. 2014;110:132-41.

44. Liao PH, Yang HH, Chou PT, Wang MH, Chu PC, Liu HL, et al. Sufficient virus-neutralizing antibody in the central nerve system improves the survival of rabid rats. J Biomed Sci. 2012;19:61.

45. Chen S, Li J, Li Q, Wang Z. Bispecific antibodies in cancer immunotherapy. Hum Vaccin Immunother. 2016;12:2491-500.

46. Wallace RM, Undurraga EA, Blanton JD, Cleaton J, Franka R Elimination of dog-mediated human rabies deaths by 2030: needs assessment and alternatives for progress based on dog vaccination. Front Vet Sci. 2017;4:9.

47. Brunker K, Marston DA, Horton DL, Cleaveland S, Fooks AR, Kazwala $\mathrm{R}$, et al. Elucidating the phylodynamics of endemic rabies virus in eastern Africa using whole-genome sequencing. Virus Evol. 2015;1:vev011.

48. Warrell MJ. Current rabies vaccines and prophylaxis schedules: preventing rabies before and after exposure. Travel Med Infect Dis. 2012;10:1-15. 